\title{
Produção sustentável e controlada de ostras: ações em Santa Catarina (Brasil) rumo aos padrões internacionais de comercialização
}

\section{Sustainable and controlled production of oysters: actions in Santa Catarina (Brazil) towards international standards of merchantability}

\author{
Bruno Jacomel ${ }^{1}$; Lucila Maria de Souza Campos ${ }^{\circledR}, 1$
}

\begin{abstract}
RESUMO
Santa Catarina posiciona-se atualmente como o segundo maior polo produtor de moluscos bivalves da América Latina. Além disso, o estado é responsável por $95 \%$ da produção nacional de moluscos bivalves. Dada a crescente importância conquistada pelo setor, este artigo tem o objetivo de analisar as ações em Santa Catarina que visam alcançar os padrões internacionais de controle, qualidade e segurança alimentar. Para tanto, foram analisados artigos publicados em revistas conceituadas, manuais, documentos técnicos e os requisitos legais previstos tanto na legislação nacional quanto internacional de comercialização de moluscos bivalves. Entre estas ações destaca-se o Plano Nacional de Controle Higiênico-Sanitário de Moluscos Bivalves, o PNCMB, criado em 2012. A análise proposta neste artigo foi feita por meio dos dados de 15 meses relativos aos parâmetros ambientais das águas de cultivo do estado, fornecidos pela CIDASC, órgão responsável pelo monitoramento. Com isso, pôdese analisar o status da atividade frente aos embargos comerciais ainda existentes para o seu desenvolvimento. Os achados da pesquisa apontam as localidades mais aptas para o desenvolvimento da atividade em Santa Catarina, suas potencialidades e necessidades em relação às exigências necessárias para efetivar-se o comércio internacional de produtos derivados do cultivo de moluscos bivalves.
\end{abstract}

Palavras-chave: Moluscos, Crassostrea gigas, Controle Sanitário.

\begin{abstract}
Santa Catarina state, located in the southern region of Brazil, currently ranks as the second largest production hub of bivalve molluscs in Latin America. In addition, the state is responsible for $95 \%$ of the national production of bivalve molluscs. Given the increasing importance gained by industry, this article aims to analyse the actions in Santa Catarina aimed at achieving international standards of control, food quality and safety. For this purpose, were analyzed articles published in reputable journals, manuals, technical documents and Legal requirements set out in both, the national and international legislation of bivalve molluscs. Among these actions, is highlighted the National Hygienic-Sanitary Shellfish Control Plan, PNCMB, created in 2012. The analysis presented in this article was taken through data (15 months) of the environmental parameters of the cultivation waters in the state, provided by CIDASC, the entity responsible for monitoring. With this, could be assessed the current situation of mollusc farming environments in the state their development and trade embargoes. The research findings suggest the most suitable areas for the development of producing molluscs in Santa Catarina, its potential and needs regarding the requirements necessary to carry up international trade in products derived from the cultivation of bivalve molluscs.
\end{abstract}

Keywords: Molluscs, Crassostrea gigas, Sanitary Control.

(a) corresponding author

${ }^{1}$ Universidade Federal de Santa Catarina (UFSC), Centro Tecnológico (CTC), Programa de Pós Graduação em Engenharia de Produção (PPGEP), Campus Universitário, Trindade, Florianópolis, SC, Brasil. e-mails: Jacomel <bjacomel@gmail.com>; Campos $<$ lucila.campos@ufsc.br>

* Submission: 3 APR 2014; Peer review: 28 APR 2014; Revised: 3 JUL 2014; Accepted: 28 AUG 2014; Available on-line: 16 SEP 2014 


\section{Introdução}

A aquicultura compreende a criação e o cultivo de organismos em ambiente aquático controlado, mediante técnicas específicas (Pyllay, 1996). Em seu último relatório, a FAO (2012) sinalizou a atividade como uma grande promessa para suprir a crescente demanda por fontes saudáveis de proteína (McCausland et al., 2006; FAO, 2012; Soniat et al., 2012; Tiller et al., 2013). Uma demonstração disso é o crescimento consistente da atividade, que registrou uma média de crescimento nas últimas três décadas de $8,8 \%$ ao ano (FAO, 2012).

Em termos financeiros, a atividade de aquicultura movimentou, no ano de 2010, US\$ 119 bilhões de dólares, o que equivale a cerca de 60 milhões de toneladas e representa quase $40 \%$ da produção mundial de pescados para o consumo humano (FAO, 2012). Neste contexto, a produção de moluscos bivalves, como é o caso do cultivo da ostra do Pacífico [Crassostrea gigas (Thunberg, 1793)], é responsável por cerca de $40 \%$ da produção da aquicultura marinha mundial que não utiliza o fornecimento de alimento (FAO, 2012). Estudos relativos a participação da atividade pesqueira e de aquicultura no cenário mundial (Tacon \& Forster, 2001; Troell, 2003; FAO, 2012; MPA, 2013) preveem um aumento exponencial da produção via aquicultura para os próximos anos, o que aumentará, também, a parcela de participação da atividade, que hoje já representa cerca de $50 \%$ do total comercializado no mundo (FAO, 2012).

O Brasil é o segundo maior produtor de moluscos bivalves da América Latina (MPA, 2013), marca esta fruto do desenvolvimento da atividade de aquicultura, que passou por avanços consideráveis somente nos últimos 10 anos. Foi neste período em que anseios históricos e respostas dignas foram concedidas aos produtores de moluscos bivalves de todo país, quando da criação e estruturação de uma Secretaria de Aquicultura e Pesca (SEAP/PR), primeiro órgão desenvolvimentista do setor e que, devido a importância da causa, levou à posterior criação do Ministério da Pesca e Aquicultura (MPA), ambos com o objetivo de fomentar e desenvolver políticas voltadas ao setor pesqueiro e da aquicultura (MPA, 2013).

Com o objetivo de organizar o conhecimento existente sobre a gestão de longo prazo para o desenvolvimento do setor produtivo da malacocultura (cultivo de moluscos), mais precisamente para a produção de ostras de Santa Catarina, para o presente artigo elaborou-se uma busca em diversas fontes de dados e literatura disponível online, abordando todos os tópicos que se relacionam com a origem e operação do Plano Nacional de Controle Higiênico-Sanitário para os Moluscos Bivalves - PNCMB. Para isso foram levantadas todas as leis, decretos, normas e instruções normativas pertinentes ao escopo da pesquisa, assim como feitas as descrições e detalhamento das doenças passíveis de controle pelo monitoramento utilizado no programa. Investigaram-se, também, quais são os parâmetros e micro-organismos regulamentados em lei para o monitoramento e detalharam-se esses limites amostrais encarados no processo de controle sanitário.

Através do histórico de monitoramentos do PNCMB, foi Possivel, então, elaborar uma discussão sobre o status das áreas de cultivo de Santa Catarina em relação às normas internacionais de comercialização de moluscos bivalves. Este diálogo possui em seu ente, caráter estratégico para o setor, visto que o Brasil ainda não está apto a exportar moluscos bivalves, já que não se enquadra nos moldes internacionais de segurança e qualidade alimentar requeridos (MPA, 2013).

$\mathrm{O}$ artigo está estruturado em mais 4 tópicos, além da introdução. O próximo tópico, enquadramento teórico apresenta os fundamentos teóricos necessários para o entendimento das discussões posteriores do artigo, sendo eles, a situação da ostreicultura brasileira, a legislação na ostreicultura e informações sobre o Programa Nacional de Controle Higiênico-Sanitário dos Moluscos Bivalves. O item seguinte trata dos materiais e métodos. O quarto tópico apresenta e discute os resultados da pesquisa e finalmente o quinto tópico apresenta as conclusões do artigo.

\section{Enquadramento teórico}

\subsection{A Situação da Ostreicultura Brasileira}

Com um litoral de mais de oito mil quilômetros de linha de costa e possuidor de $12 \%$ de toda a reserva de água doce do planeta, o Brasil exibe um enorme potencial para o desenvolvimento da atividade de aquicultura em todo o seu território. Segundo a OMS (Organização Mundial da Saúde), o consumo médio de pescados recomendado para a manutenção correta da saúde é de $12 \mathrm{~kg}$ habitante/ano. O Brasil ainda não alcançou este patamar, embora tenha registrado, no ano de 2009, a média de $9 \mathrm{~kg}$ habitante/ano, sendo que a meta governamental para esta marca era esperada somente para o ano de 2011. Logo, ações para o estímulo ao consumo de pescados, assim como para o aumento gradativo do setor produtivo e extrativista vêm sendo elaborados (MPA, 2013).

Em uma esfera nacional, a produção de pescados vem sofrendo grandes transformações ao longo dos últimos 30 anos. Neste contexto podem-se citar algumas iniciativas, como a criação da SEAP/PR (Secretaria da Aquicultura e Pesca / Presidência da República), ocorrida em 2003, e a resolução IN n..$^{0} 6$, que garante a Cessão de águas da União para atividades produtivas 
como a aquicultura. Tais iniciativas serviram como importantes gatilhos para a alavancagem produtiva, fomento e criação de políticas voltadas ao setor pesqueiro no conjunto de seus anseios. A própria criação do Ministério da Pesca e Aquicultura (MPA), ocorrida em 2009, ajudou ainda mais a organizar o setor pesqueiro e de aquicultura com uma nova política de gestão e ordenamento do setor, mantendo o compromisso com a sustentabilidade ambiental no uso dos recursos pesqueiros.

Em uma análise levando-se em conta as regiões brasileiras produtoras de pescados, a região Nordeste é atualmente a maior produtora de pescados (MPA, 2013). Isto muito se deve ao aumento da produção de peixes nativos e camarão naquela região. Já a região sul, que está em segundo lugar, é caracterizada principalmente pela produção de peixes de água doce e de moluscos. Uma vez dentro das características produtivas da região Sul, tem-se a grande representatividade da produção de moluscos bivalves. No caso específico do estado de Santa Catarina, que é responsável por cerca de $95 \%$ da produção nacional de moluscos bivalves para o comércio, pode-se destacar o cultivo de algumas espécies que foram selecionadas ao longo dos anos por suas características fisiológicas de crescimento e adaptativas ao clima dessa região, possibilitando sua produção em escala comercial.

Esta seleção levou à escolha da ostra Crassostrea gigas, também conhecida como ostra japonesa ou ostra do Pacífico. Neste setor, o estado de Santa Catarina emerge como o principal produtor nacional na atualidade. Levantamentos realizados no estado no ano de 2012, registraram uma produção de 2.468 toneladas de ostras (C. gigas), 13.753 toneladas de mexilhões (Perna perna) e 5,6 toneladas de vieiras (Nodipecten nodosus) (Santos, 2013). Diante da importância que o estado de Santa Catarina tem em termos de produção de moluscos bivalves, fazem-se necessárias ações que prezem pela manutenção a longo prazo desta atividade, visto que quando mal gerido, o cultivo destes organismos pode afetar o meio ambiente (Goni, 1998; Humphrey, 2000; Cicin-Sain \& Belfiore, 2005; ICES, 2009; Rangeley \& Davies, 2012). Além disso, a utilização dos recursos naturais disponíveis é simultaneamente, em muitos casos, compartilhada por vários cultivos, atividades e stakeholders (parte interessada ou interveniente) (Buanes et al., 2005; Thorpe et al., 2005; Tiller et al., 2013), fazendo com que a preocupação sobre o correto andamento dos métodos mitigatórios dos impactos ambientais e sociais gerados pelos cultivos sejam cada vez mais incorporados ao desenvolvimento das comunidades que se utilizam da produção de moluscos bivalves para subsistência (Vianna et al., 2012).

\subsection{A Situação da Ostreicultura Brasileira}

As leis que regem o setor da aquicultura, mais precisamente o ramo da produção de moluscos bivalves, como é o caso da ostreicultura, são de origem recente. Também por isso, o ordenamento da atividade, entre outros temas básicos para se estruturar um setor produtivo, ainda está em seu período de amadurecimento. Isto dificulta, em parte, a realização de prognósticos eficientes sobre os entraves e gargalos para o desenvolvimento sustentável da atividade.

A própria criação do Ministério da Pesca e Aquicultura (MPA) remete a não mais que quatro anos atrás, mais precisamente a 29 de julho de 2009, quando foi sancionada a Lei $\mathrm{n}^{0} 11.958$ pelo então presidente da República, Luiz Inácio Lula da Silva. Alternativamente, os trabalhos para a estruturação do setor já vinham sendo realizados pela Secretaria Especial da Aquicultura e Pesca (SEAP/PR), entidade criada em $1^{\underline{o}}$ de janeiro de 2003. Este órgão, por sua vez, foi o primeiro oficial do setor e responsável por fomentar e desenvolver políticas voltadas ao setor pesqueiro (MPA, 2013). Ainda hoje é um órgão ligado à presidência da república e criado através da Lei n⿳0 10.683 (MPA, 2013).

Outro momento importante foi a $2^{\circ}$ Conferência Nacional de Aquicultura e Pesca, promovida pela SEAP/PR e pelo Conselho Nacional de Desenvolvimento da Aquicultura e Pesca (CONAPE) em 2006. Com o tema "Consolidação da Política Nacional de Aquicultura e Pesca", este encontro promoveu mudanças no paradigma da atividade. Entre suas resoluções, foi aprovada a proposta de centralização de todas as competências relativas ao desenvolvimento do setor em um único órgão de governo e a transformação da SEAP/PR em Ministério (MPA, 2013).

Dando sequência ao esqueleto legislativo sobre as iniciativas em prol do desenvolvimento sustentável e da padronização dos processos produtivos nas atividades relacionadas à produção de moluscos bivalves, este artigo incluiu em seu escopo a seleção dos regulamentos, tanto por parte das entidades regulatórias do Brasil como da União Europeia. A escolha deste conglomerado de países se deu pela importância em termos de mercado consumidor, uma vez que a UE constitui um dos maiores importadores de pescados no mundo. Para isso foi elaborada a tabela abaixo (Tabela 1), que pretende abranger as principais iniciativas legislativas atuais que visam este desenvolvimento para a atividade no Brasil.Dentre as normativas discriminadas na tabela 1 como pertinentes ao desenvolvimento sustentável ordenado e padronizado pretendido pelos órgãos governamentais e setor privado, destaca-se a criação do Plano Local de Desenvolvimento da Maricultura, o PLDM, iniciado em 2003 pelo Decreto 
Tabela 1 - Normativas referentes ao projeto de padronização da produção de moluscos de Santa Catarina. Table 1 - Regulations related to the project of standardization of the production of molluscs in Santa Catarina

\begin{tabular}{|c|c|c|c|}
\hline Ano & Tipo & Descrição & Observação \\
\hline 2003 & $\begin{array}{c}\text { Lei } \mathrm{n}^{\circ} 10.683 \\
\text { de } 1 \text { de Janeiro de } 2003 \text {. }\end{array}$ & $\begin{array}{l}\text { Dispõe sobre a organização da Presidência da } \\
\text { República e dos Ministérios, e dá outras } \\
\text { providências. }\end{array}$ & Criação da SEAP-PR \\
\hline 2003 & $\begin{array}{c}\text { Decreto } n^{\circ} 4.895 \\
\text { de } 25 \text { de Novembro de } 2003 \text {. }\end{array}$ & $\begin{array}{l}\text { Dispõe sobre a autorização de uso de espaços } \\
\text { físicos de corpos d'água de domínio da } \\
\text { União para fins de aquicultura, e dá outras } \\
\text { providências. }\end{array}$ & $\begin{array}{l}\text { Institui o ordenamento para as } \\
\text { atividades de maricultura. }\end{array}$ \\
\hline 2005 & $\begin{array}{c}\text { Decreto } \mathrm{n}^{\circ} 5.564 \\
\text { de } 19 \text { de Outubro de } 2005 \text {. }\end{array}$ & $\begin{array}{l}\text { Dispõe sobre a criação do Comitê Nacional de } \\
\text { Controle Higiênico-Sanitário de Moluscos } \\
\text { Bivalves - CNCMB e dá outras provi- } \\
\text { dências. }\end{array}$ & $\begin{array}{l}\text { Institui o CNCMB para fins de } \\
\text { desenvolver o controle e } \\
\text { padronização da produção } \\
\text { brasileira de moluscos bivalves }\end{array}$ \\
\hline 2006 & $\begin{array}{l}\text { Instrução Normativa - } \\
\text { IBAMA no } 105 \\
\text { de } 15 \text { de Julho de } 2006 .\end{array}$ & $\begin{array}{l}\text { Dispõe regras de ordenamento pesqueiro para } \\
\text { a extração de moluscos bivalves prove- } \\
\text { nientes de estoques naturais e procedi- } \\
\text { mentos para a instalação de empreendi- } \\
\text { mentos de Malacocultura em Aguas de } \\
\text { domínio da União. }\end{array}$ & $\begin{array}{l}\text { Institui um período de defeso da } \\
\text { captura de moluscos bivalves } \\
\text { do ambiente natural. }\end{array}$ \\
\hline 2009 & $\begin{array}{c}\text { Lei }{ }^{\circ} 11.958 \\
\text { de } 26 \text { de Junho de } 2009 .\end{array}$ & $\begin{array}{l}\text { Dispõe sobre a transformação da Secretaria } \\
\text { Especial de Aquicultura e Pesca da Presi- } \\
\text { dência da República em Ministério da Pesca } \\
\text { e Aquicultura entre outras providências. }\end{array}$ & $\begin{array}{l}\text { Transformação da SEAP-PR em } \\
\text { MPA }\end{array}$ \\
\hline 2009 & $\begin{array}{l}\text { Resolução CONAMA no } 413 \\
\text { de } 26 \text { de junho de } 2009 .\end{array}$ & $\begin{array}{l}\text { Dispõe sobre o licenciamento ambiental em } \\
\text { aquicultura e dá outras providências. }\end{array}$ & $\begin{array}{l}\text { Institui conceitos (ex. aquicultura, } \\
\text { área aquícola, etc.), define } \\
\text { procedimentos para licencia- } \\
\text { mento. Foi alterada pela Reso- } \\
\text { lução } n^{\circ} 459 / 2013 \text {. }\end{array}$ \\
\hline 2012 & $\begin{array}{l}\text { Instrução Normativa } \\
\text { Interministerial no } 3 \text {, } \\
\text { de } 3 \text { de Abril de } 2012 \text {. }\end{array}$ & $\begin{array}{l}\text { Institui a Rede Nacional de Laboratórios do } \\
\text { Ministério da Pesca e Aquicultura - } \\
\text { RENAQUA. }\end{array}$ & $\begin{array}{l}\text { Criação RENAQUA para análises } \\
\text { das amostras feitas no CNCMB. }\end{array}$ \\
\hline 2012 & $\begin{array}{l}\text { Instrução Normativa } \\
\text { Interministerial } \mathrm{n}^{\circ} 7 \text {, } \\
\text { de } 8 \text { de Maio de } 2012 \text {. }\end{array}$ & $\begin{array}{l}\text { Institui o Programa Nacional de Controle } \\
\text { Higiênico-Sanitário de Moluscos Bivalves } \\
\text { (PNCMB), estabelece os procedimentos } \\
\text { para a sua execução e dá outras provi- } \\
\text { dências. }\end{array}$ & $\begin{array}{l}\text { Inicio dos trabalhos para se } \\
\text { alcançar os padrões requeridos } \\
\text { internacionalmente para a ex- } \\
\text { portação de moluscos bivalves. }\end{array}$ \\
\hline 2013 & $\begin{array}{c}\text { Portaria } \mathrm{n}^{\circ} 175, \\
\text { de } 15 \text { de Maio de } 2013 .\end{array}$ & $\begin{array}{l}\text { Acresce dispositivos à Portaria MPA n }{ }^{\circ} 204 \text {, } \\
\text { de } 28 \text { de junho de } 2012 \text {. }\end{array}$ & $\begin{array}{l}\text { Define valores numéricos para } \\
\text { retirada de moluscos do mer- } \\
\text { cado. }\end{array}$ \\
\hline
\end{tabular}

n⿳⺈ 4.895. A partir daí, deu-se o início da organização e gestão básica da atividade no Brasil. Santa Catarina foi o primeiro estado no país a tramitar licenças para a regularização dos parques aquícolas e áreas pretendidas ao cultivo. Apesar do início dos trabalhos relativos ao PLDM terem ocorrido há 10 anos, somente a partir de 2008 é que começaram a tramitar os pedidos de licenciamento no órgão licenciador responsável, o Instituto Brasileiro do Meio Ambiente e dos Recursos Naturais Renováveis - IBAMA. Com isso puderam ser efetivadas áreas constitucionais de produção de ostras, garantindo assim, entre outras coisas, a inserção da atividade nas políticas públicas de apoio à produção, como aquelas concedidas aos agricultores e pescadores.

Outro ponto que vale ser ressaltado é a deliberação da Instrução Normativa Interministerial (IN) $\mathrm{n}^{-} 7$, publicada em 8 de outubro de 2012. A partir dessa decisão efetivou-se o início das atividades de monitoramento e controle higiênico-sanitário para a atividade de produção de moluscos bivalves no Brasil. Mais uma vez, Santa Catarina foi pioneira na consolidação desta política pública, tendo como parceria a Companhia Integrada de Desenvolvimento Agrícola de Santa Catarina - CIDASC, que ficou responsável pela coleta das amostras necessárias e envio das mesmas aos laboratórios licenciados. Com esta iniciativa posta em prática, a meta de equiparar a produção de moluscos bivalves aos moldes internacionais de produção ficou mais próxima, padrão muito almejado pelos produtores locais (MPA, 2013).

Traçando um paralelo entre os sistemas de desenvolvimento e controle higiênico-sanitário animal utilizados em outros países que são referência na produção de moluscos bivalves, consideramos o mercado unificado constituído pelos 28 países integrantes da União Europeia um exemplo adequado a seguir. Através da análise sobre a legislação vigente neste conglomerado, torna-se 
possível identificar quais são os métodos, procedimentos e índices utilizados por um dos maiores mercados importadores de pescados e moluscos bivalves, como a ostra, atualmente.

Dentro do escopo do presente artigo, foram levantados os regulamentos em vigência naquela organização e para fins didáticos foi elaborada uma tabela (Tabela 2), a qual discrimina quais normativas constroem o atual paradigma regulatório sobre a padronização, controle e segurança alimentar, exigidas para fins de comercialização de moluscos bivalves.

Através de uma análise dos parâmetros e índices utilizados tanto pelas normas brasileiras, instituídas pela $\mathrm{IN} \mathrm{n}^{-}$ 7, quanto pelos regulamentos do Conselho Europeu (CE) deliberados pelo Parlamento Europeu, puderam-se verificar semelhanças entre os métodos de análise institucionalizados pelas duas partes. A primeira diz respeito à utilização do HACCP (Hazard Analysis and Critical Control Points - Análise dos Perigos e Pontos Críticos de Controle) como procedimento analítico aceitável (Inácio, 2008), uma vez que este sistema é amplamente reconhecido em termos de segurança e controle alimentar em todo o mundo.

Parâmetros inerentes à boa qualidade dos moluscos bivalves são descritos nos regulamentos (CE) no $2073 \mathrm{e}$ $\mathrm{n}^{\mathrm{o}}$ 2074, ambos publicados no ano de 2005 pelo CE. O primeiro discrimina os índices numéricos relativos aos critérios microbiológicos aplicáveis aos gêneros alimentícios, incluindo os moluscos bivalves. Neste regulamento são descritos os métodos aceitos para detecção

Tabela 2 - Normativas utilizadas pela União europeia referentes à importação de moluscos bivalves.

Table 2 - Regulations used by the European Union regarding the import of bivalve molluscs.

\begin{tabular}{|c|c|c|c|}
\hline Ano & Tipo & Descrição & Observação \\
\hline 2001 & $\begin{array}{l}\text { Regulamento (CE) n }{ }^{\circ} 2065 \\
\text { de } 22 \text { de Outubro de } 2001 .\end{array}$ & $\begin{array}{l}\text { Estabelece as regras de execução do } \\
\text { Regulamento (CE) n } 104 / 2000 \text { do } \\
\text { Conselho no respeitante à informação } \\
\text { do consumidor no setor dos produtos } \\
\text { da pesca e da aquicultura. }\end{array}$ & $\begin{array}{l}\text { Inclui informações relevantes } \\
\text { ao consumidor de pescados. }\end{array}$ \\
\hline 2004 & $\begin{array}{l}\text { Regulamento (CE) no } 852 \text { do } \\
\text { Parlamento Europeu e do Conselho } \\
\text { de } 29 \text { de Abril de } 2004 .\end{array}$ & $\begin{array}{l}\text { Dispõe sobre a metodologia a ser empre- } \\
\text { gada para manutenção da higiene dos } \\
\text { gêneros alimentícios. }\end{array}$ & $\begin{array}{l}\text { Institui o HACCP como méto- } \\
\text { do de controle. }\end{array}$ \\
\hline 2004 & $\begin{array}{l}\text { Regulamento }(\mathrm{CE}) \mathrm{n}^{\circ} 853 \text { do } \\
\text { Parlamento Europeu e do Conselho } \\
\text { de } 29 \text { de Abril de } 2004 .\end{array}$ & $\begin{array}{l}\text { Estabelece regras específicas de higiene } \\
\text { aplicáveis aos gêneros alimentícios de } \\
\text { origem animal. }\end{array}$ & $\begin{array}{l}\text { Determina o que são moluscos } \\
\text { bivalves segundo as normas } \\
\text { vigentes. }\end{array}$ \\
\hline 2004 & $\begin{array}{l}\text { Regulamento (CE) n }{ }^{\circ} 854 \text { do } \\
\text { Parlamento Europeu e do Conselho } \\
\text { de } 29 \text { de Abril de } 2004 .\end{array}$ & $\begin{array}{l}\text { Estabelece regras específicas de organi- } \\
\text { zação dos controlos oficiais de produ- } \\
\text { tos de origem animal destinados ao } \\
\text { consumo humano. }\end{array}$ & $\begin{array}{l}\text { Determina as áreas de controle, } \\
\text { classifica zonas de produção } \\
\text { entre outros. }\end{array}$ \\
\hline 2005 & $\begin{array}{l}\text { Regulamento (CE) n }{ }^{\circ} 2073 \\
\text { de } 15 \text { de Novembro de } 2005 .\end{array}$ & $\begin{array}{l}\text { Dispõe sobre critérios Microbiológicos } \\
\text { aplicáveis aos gêneros alimentícios. }\end{array}$ & $\begin{array}{l}\text { Discrimina índices numéricos } \\
\text { aos moluscos. }\end{array}$ \\
\hline 2005 & $\begin{array}{l}\text { Regulamento (CE) no } 2074 \\
\text { de } 05 \text { de Dezembro de } 2005 \text {. }\end{array}$ & $\begin{array}{l}\text { Dispõe sobre métodos de execução para } \\
\text { determinados produtos de origem } \\
\text { animal descritos nos Regulamentos } \\
\text { (CE) anteriores. }\end{array}$ & $\begin{array}{l}\text { Procedimentos metodológicos } \\
\text { para a análise Microbiológica } \\
\text { e de toxinas em moluscos. }\end{array}$ \\
\hline 2006 & $\begin{array}{l}\text { Decisão da Comissão (CE) n }{ }^{\circ} 766 \\
\text { de } 6 \text { de Novembro de } 2006 .\end{array}$ & $\begin{array}{l}\text { Estabelece a lista de países terceiros e } \\
\text { territórios a partir dos quais são autori- } \\
\text { zadas as importações de moluscos } \\
\text { bivalves, equinodermos, tunicados, } \\
\text { gastrópodes marinhos e produtos da } \\
\text { pesca. }\end{array}$ & $\begin{array}{l}\text { Brasil autorizado a exportar } \\
\text { produtos oriundos da pesca. } \\
\text { Não moluscos. }\end{array}$ \\
\hline 2007 & $\begin{array}{l}\text { Regulamento } n^{0} 1244 \\
\text { de } 24 \text { Outubro de } 2007 \text {. }\end{array}$ & $\begin{array}{l}\text { Altera o regulamento n 2074/2005 no } \\
\text { que se refere às medidas de execução } \\
\text { aplicáveis a determinados produtos de } \\
\text { origem animal. }\end{array}$ & $\begin{array}{l}\text { Define métodos de avaliação de } \\
\text { toxinas (ASP) para moluscos } \\
\text { bivalves. }\end{array}$ \\
\hline 2011 & $\begin{array}{l}\text { Regulamento (UE) } \mathrm{n}^{\circ} 15 \\
\text { de } 10 \text { de Janeiro de } 2011 .\end{array}$ & $\begin{array}{l}\text { Altera o Regulamento }(\mathrm{CE}) \mathrm{n}^{\circ} 2074 / 2005 \\
\text { no que diz respeito aos métodos de } \\
\text { análise reconhecidos para detectar bio- } \\
\text { toxinas marinhas em moluscos bival- } \\
\text { ves vivos. }\end{array}$ & $\begin{array}{l}\text { Detalha novos métodos de Ava- } \\
\text { liação para deteç̧ão de bioto- } \\
\text { xinas. }\end{array}$ \\
\hline
\end{tabular}


da Escherichia coli e Estafilococos coagulase no produto, para enquadramento aos requisitos de importação. Com relação a estes critérios, a contagem de "coliformes totais" foi substituída pela contagem de E. coli, quer para os critérios de segurança dos gêneros alimentícios (Reg. CE n. ${ }^{\circ}$ 2073/2005), quer para a classificação das zonas de produção (Reg. CE n. ${ }^{\circ}$ 854/2004) (Inácio, 2008).

Por sua vez, o Regulamento (CE) $\mathrm{n}^{\mathrm{o}} 2074$ descreve os métodos de análise para a detecção de biotoxinas nos moluscos bivalves. São listadas as biotoxinas dos tipos Amnésica (ASP), Paralisante (PSP) e Lipofílicas (grupos AO, YTX e AZA) e disponibilizados dois tipos de análise, uma através da utilização de métodos biológicos (que se serve de testes em animais) e outro, alternativo, que se vale da cromatografia líquida de alta resolução (HPLC). O próprio regulamento incentiva a substituição das análises biológicas pelo HPLC, sem a utilização de cobaias, quando disponíveis os reagentes necessários e a validação destes testes por padrões de qualidade credenciados.

O Regulamento (CE) $\mathrm{n}^{0} 854$ determina pontos de controle dentro do processamento de moluscos bivalves. Este mesmo regulamento ainda classifica as regiões produtoras para autorizar categorias de comércio de moluscos bivalves com a União Europeia. Atualmente os moluscos bivalves vivos capturados em zonas de produção classificadas como $\mathrm{C}$, apenas podem ser colocados no mercado após um longo período de monitoramento do meio natural ou, em alternativa, encaminhados para a indústria de processamento, onde serão sujeitos a tratamento térmico específico (capítulo II, do anexo II, do Reg. CE n. ${ }^{\circ}$ 854/2004). Segundo Inácio (2008), a regulamentação anterior permitia que estes moluscos bivalves vivos fossem sujeitos a uma depuração prolongada, que nunca foi regulamentada, existindo alguns operadores para os quais estes produtos representavam uma parcela importante da matéria-prima utilizada nos seus centros de depuração.

Outra das alterações introduzidas refere-se à atividade dos centros de expedição, que atualmente apenas podem expedir produto salubre (parte $\mathrm{B}$, capítulo IV, da secção VII, do anexo III, do Reg. CE n. ${ }^{\circ}$ 853/2004) (Inácio, 2008). Isto é, apenas podem expedir moluscos bivalves vivos provenientes de uma zona de produção classificada como A, de uma zona de afinação, de um centro de depuração ou de outro centro de expedição. Não é, assim, possível a estes centros a expedição de produto insalubre moluscos bivalves vivos capturados em zonas de produção classificadas como B ou C) embalado destinado a um centro de depuração ou para a indústria, como acontecia outrora.

Já pela regulamentação brasileira (PNCMB), tema que será melhor discutido adiante, há uma lista detalhada das toxinas marinhas e microbiológicas a serem analisadas com a finalidade de enquadramento no programa.
Foram listadas as toxinas do tipo Amnésica (ASP), Paralisante (PSP), Lipofílicas (grupos AO, YTX e AZA), Diarreica (DSP) e Azaspirácido (AZP). Importante destacar que estes contaminantes foram listados em conformidade a regulamentos europeus de controle sanitário animal, como os descritos no Regulamento CE no 1244/2007 e Regulamento UE no 15/2011 e padrões internacionais estabelecidos na ISO $16.140 \mathrm{e}$ ISO/TS 16.649-3 e AESA (Autoridade Europeia para a Segurança Alimentar). Dentro desta perspectiva, tornase simples traçar um paralelo entre os parâmetros requeridos internacionalmente com os índices utilizados atualmente no país, visto que a legislação brasileira está baseada nas normas internacionais de segurança e qualidade alimentar.

\subsection{O Programa Nacional de Controle Higiênico- Sanitário dos Moluscos Bivalves - PNCMB}

As iniciativas governamentais em prol do aumento da segurança alimentar para o consumo humano são, em grande parte, respostas de forma regulatória às tentativas de acabar com o comércio clandestino e principalmente de padronizar aspectos básicos dentro da produção de moluscos, ocorrida em muitos países nos últimos 20 anos. $\mathrm{O}$ início destas medidas normativas se deu no final da década de 80, nos Estados Unidos, através de seu órgão regulador, a U.S. Food and Drug Administration (FDA), um dos órgãos mais antigos neste segmento no mundo. Foi neste período que se implantaram monitoramentos mais restritivos à produção e importação de produtos oriundos da pesca e aquicultura, como é o caso dos moluscos bivalves. O motivo, mais uma vez, veio por conta do registro de muitos casos de problemas à saúde humana envolvendo o consumo de pescados.

Desde então, muitos países vêm desenvolvendo constantes atualizações em seus procedimentos a fim de assegurar a segurança alimentar humana. Dentro da União Europeia existem leis envolvendo o tema há bastante tempo. Mas somente no ano de 2004 é que a União Europeia, em conjunto com seu conselho (CE), atualizou as publicações relativas à segurança alimentar de forma mais intensa. Naquele ano foi lançado o que vem sendo chamado de "pacote de higiene", um conjunto de regulamentos que trouxeram significativas mu-danças nos procedimentos de importação, principal-mente para o setor dos moluscos bivalves (Inácio, 2008).

Estes regulamentos referentes ao "pacote" foram constituídos de três regulamentos (Reg. CE $\mathrm{n}^{\text {o }}$ 852/2004; Reg. CE no 853/2004 e Reg. CE no $854 / 2004$ ), através dos quais se instituíram novas definições do que são propriamente os moluscos bivalves para efeito da lei; determinaram-se as zonas produtoras do produto; fez-se uma classificação entre zonas $(\mathrm{A}, \mathrm{B}, \mathrm{C})$ e detalharam-se também os procedimentos analíticos necessários para se enquadrar um 
produto oriundo da ostreicultura ao mercado europeu de importação. Alguns ajustes foram feitos após a publicação destes regulamentos do "pacote" e neste âmbito é que, em 10 janeiro de 2011, mais uma vez a UE publicou o Regulamento no 15, que propõe novos métodos de avaliação para a detecção de biotoxinas marinhas para os moluscos bivalves.

Tendo como referência estas normas internacionais de segurança alimentar é que foi estruturado o PNCMB no Brasil, programa este criado pela Instrução Normativa Interministerial $\mathrm{n}^{\circ} 7$ de 8 de maio de 2012 em uma parceria entre o MPA e Ministério da Agricultura, Pecuária e Abastecimento (MAPA). Uma norma importante neste contexto diz respeito à Portaria $n^{\circ} 204$, de 28 de junho de 2012, que estabelece os procedimentos para coleta de amostras para realização de análises de micro-organismos contaminantes e de toxinas marinhas em moluscos bivalves e de análises para o monitoramento de espécies de microalgas potencialmente produtoras de biotoxinas (MPA, 2013).

Com a finalidade de facilitar o acesso e entendimento quanto às questões que abrangem a execução do referido programa, foi lançado em 2013 o Manual do MPA para o PNCMB, que inclui o manual de coleta e remessa de amostras oficiais do PNCMB e orientações para a definição da retirada de moluscos bivalves nas áreas de extração ou cultivo (MPA, 2013). Este manual tem como objetivo padronizar os procedimentos de coleta e remessa de amostras no âmbito do PNCMB e estabelecer os critérios a serem utilizados para a definição de retirada de moluscos bivalves dos ambientes de cultivos para venda. A tabela 3 apresenta os valores indicados pela legislação brasileira que indicam medidas limites para a classificação quanto à qualidade dos moluscos em relação ao monitoramento tanto das biotoxinas marinhas como dos micro-organismos contaminantes (E. coli).

Os resultados existentes nesta classificação são enquadrados em três categorias:
- Retirada Liberada (apresentam valores inferiores aos limites exigidos por lei);

- Retirada Liberada sob condição (faz-se necessária uma etapa intermediária de depuração antes da venda dos produtos);

- Retirada Suspensa (necessária a retirada dos produtos daquela área do mercado).

O PNCMB pretende abranger todas as etapas posteriores ao cultivo que se caracterizam pela retirada, manuseio, processamento e transporte de moluscos bivalves destinados ao consumo humano. Ao MPA cabe o monitoramento de micro-organismos e de biotoxinas marinhas, e ao MAPA (Ministério da Agricultura, Pecuária e Abastecimento) cabe a fiscalização e a inspeção industrial dos processadores de moluscos bivalves que tenham certificação do MPA (MPA, 2013). Com isso espera-se garantir o controle e padronização da produção de moluscos bivalves desde a coleta das amostras que serão encaminhadas aos laboratórios, até ao envio dos animais para o beneficiamento em locais com inspeção pelo médico veterinário (MPA, 2013).

A Instrução Normativa $\mathrm{n}^{\circ} 3$ de 3 de abril de 2012 instituiu a criação da Rede Nacional de Laboratórios do Ministério da Pesca e Aquicultura - RENAQUA, rede esta criada para auxiliar a execução do PNCMB. A ela cabe a realização de diagnósticos e análises oficiais, bem como o desenvolvimento contínuo de novas metodologias para exames de doenças, resíduos e contaminantes. A rede vem sendo estruturada segundo padrões internacionais de qualidade laboratorial, estabelecidos pelo padrão ISO 17.025 e dará suporte aos programas sanitários do MPA através de convênios com grandes laboratórios já existentes e credenciados pelos órgãos licenciadores no Brasil.

O monitoramento sistemático das áreas de cultivo é realizado justamente para verificar se é seguro ou não proceder à retirada dos moluscos. Neste sentido, o MPA

Tabela 3 - Critérios para a definição da retirada de moluscos bivalves. Fonte: MPA, 2013.

Table 3 - Criteria for defining the removal of bivalve molluscs. Source: MPA, 2013.

\begin{tabular}{|c|c|c|c|c|c|c|}
\hline \multirow{2}{*}{ Retirada Liberada } & $\begin{array}{c}\text { NMP para E.coli em } \\
100 \text { gramas }(\mathrm{g}) \mathrm{da} \\
\text { parte comestível dos } \\
\text { moluscos bivalves. }\end{array}$ & \multicolumn{5}{|c|}{$\begin{array}{c}\text { Limites de biotoxinas produzidas por microalgas em } 1 \text { quilograma (kg) da } \\
\text { parte comestível dos moluscos bivalves }\end{array}$} \\
\cline { 2 - 7 } & E. Coli & PSP & DSP & DSP & ASP & AZP \\
\cline { 2 - 7 } & $<230$ & $\begin{array}{c}<0,8 \mathrm{mg} \\
(\mathrm{eq}-\mathrm{STX})\end{array}$ & $\begin{array}{c}<0,16 \mathrm{mg} \\
(\mathrm{eq}-\mathrm{AO})\end{array}$ & $\begin{array}{c}<1 \mathrm{mg} \\
(\mathrm{eq}-\mathrm{YTX})\end{array}$ & $\begin{array}{c}<20 \mathrm{mg} \\
(\mathrm{AD})\end{array}$ & $\begin{array}{c}<0,16 \mathrm{mg} \\
(\mathrm{eq}-\mathrm{AZA} 1)\end{array}$ \\
\hline $\begin{array}{c}\text { Retirada liberada } \\
\text { sob condição }\end{array}$ & $230 \leq \mathrm{NMP} \leq 46.000$ & $\begin{array}{c}<0,8 \mathrm{mg} \\
(\mathrm{eq}-\mathrm{STX})\end{array}$ & $\begin{array}{c}<0,16 \mathrm{mg} \\
(\mathrm{eq}-\mathrm{AO})\end{array}$ & $\begin{array}{c}<1 \mathrm{mg} \\
(\mathrm{eq}-\mathrm{YTX})\end{array}$ & $\begin{array}{c}<2 \mathrm{mg} \\
(\mathrm{AD})\end{array}$ & $\begin{array}{c}<0,16 \mathrm{mg} \\
(\mathrm{eq}-\mathrm{AZA} 1)\end{array}$ \\
\hline Retirada Suspensa & $>46.000$ & $\begin{array}{c}\geq 0,8 \mathrm{mg} \\
(\mathrm{eq}-\mathrm{STX})\end{array}$ & $\begin{array}{c}\geq 0,16 \mathrm{mg} \\
(\mathrm{eq}-\mathrm{AO})\end{array}$ & $\begin{array}{c}\geq 1 \mathrm{mg} \\
(\mathrm{eq}-\mathrm{YTX})\end{array}$ & $\begin{array}{c}\geq 20 \mathrm{mg} \\
(\mathrm{AD})\end{array}$ & $\begin{array}{c}\geq 0,16 \mathrm{mg} \\
(\mathrm{eq}-\mathrm{AZA} 1)\end{array}$ \\
\hline \hline
\end{tabular}


determina um plano amostral programado, no qual são realizadas coletas periódicas para a realização de análises. A amostragem é realizada em locais georreferenciados de cultivo e/ou extração de moluscos bivalves (MPA, 2013). Outro ponto importante a ser considerado sobre o PNCMB, diz respeito aos resultados das análises que garantem a retirada dos moluscos ou sua liberação. Pois, além destas duas categorias, existe também a possibilidade da retirada ser liberada sob condição, o que significa que os moluscos deverão passar por um processo de depuração e/ou tratamento térmico, dependendo da gravidade dos resultados colhidos em campo daquela área específica.

A efetiva realização empírica do monitoramento se dá por meio de agências ou órgãos estaduais de defesa sanitária animal que firmaram convênio com o MPA. Cabe destacar que a CIDASC já possui convênio firmado com o MPA para executar o PNCMB no estado de Santa Catarina. Em um primeiro momento, quatro laboratórios de instituições públicas de pesquisa, ensino e extensão e de órgãos executores de defesa sanitário animal estaduais já integram o sistema: o da Universidade Federal de Minas Gerais (UFMG), da Universidade Estadual do Maranhão (UEMA), do Instituto Federal de Santa Catarina (IFSC) e da Companhia Integrada de Desenvolvimento Agrícola de Santa Catarina (CIDASC).

Dentro das metas e características da produção brasileira, este programa foi elaborado com o intuito de monitorar toda a produção da malacocultura destinada ao consumo humano, como ostras, berbigões, vieiras e mexilhões. Dentro desta esfera poderia se fazer a análise com base em qualquer destes moluscos; porém dada a importância da produção de ostras e mexilhões no estado, o PNCMB tem enfatizado as análises oriundas da carne desses bivalves.

\section{Material e métodos}

Para a reunião dos dados utilizados por esta pesquisa e fundamentação dos procedimentos e métodos necessários para a elaboração das análises feitas, utilizou-se a base de dados e histórico de resultados da CIDASC. Esta entidade também é responsável pelas coletas amostrais em todas as regiões produtoras de moluscos do estado. Com base neste plano, e em seus alicerces legais, fundamentou-se a pesquisa e discussão sobre o status da atividade quanto ao seu desenvolvimento ordenado e monitorado. Estas análises também possibilitaram a identificação das potencialidades dos locais produtivos no estado, suas carências na gestão deste plano e necessidades futuras para a manutenção do crescimento sustentável da atividade.

A Figura 1 apresenta a área de localização, pontos de coleta e área abrangida pela pesquisa. A presente pesquisa dividiu-se em três etapas distintas para sua concretização. Foram elas as etapas 1, focada na pesquisa e exploração do conteúdo teórico utilizado; a etapa 2, focada na análise deste material teórico e sua comparação aos dados ambientais das águas de Santa Catarina e a etapa 3, focada na interpretação destes dados ambientais, possibilitando verificar as potencialidades das áreas produtivas de moluscos em Santa Catarina.

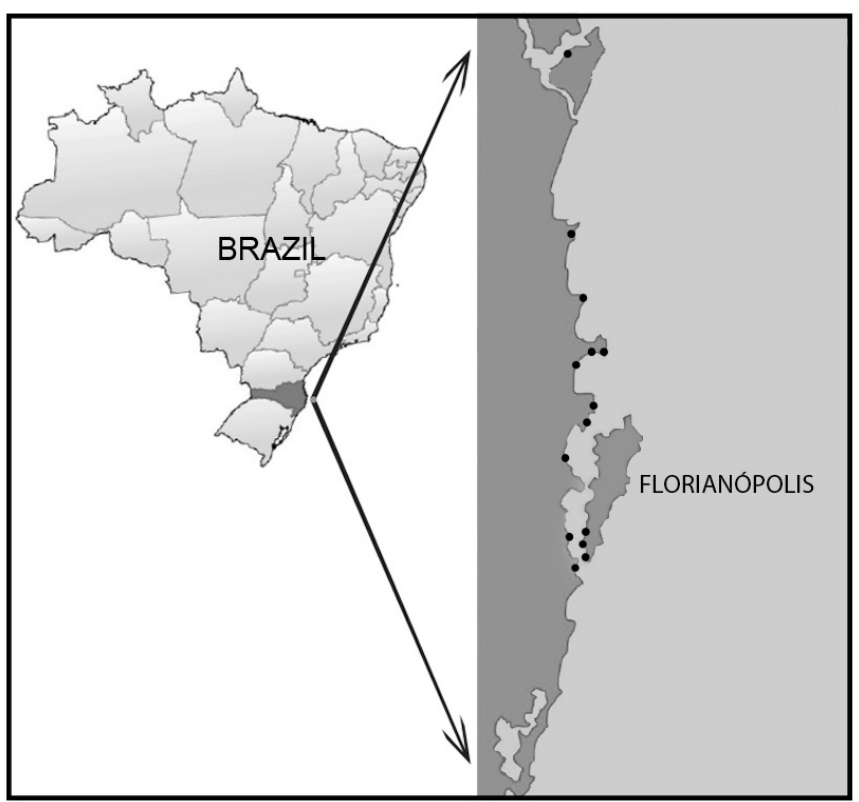

Figura 1 - Área de localização, pontos de coleta e área abrangida pela pesquisa.

Figure 1 - Area location, collection points and area covered by the survey.

Assim, na etapa 1 (figura 2), que teve o foco na elaboração da estrutura conceitual em que se baseou a fundamentação teórica, foram consultados artigos publicados, materiais técnicos e legais relativos à produção de moluscos bivalves e suas bases legislativas.

Alguns dos tópicos investigados foram: iniciativas sustentáveis na produção de moluscos bivalves, gestão da produção e normas que regulamentam o setor. Através da seleção pela leitura dos mesmos chegou-se a cerca de 40 artigos, que fazem parte direta ou indiretamente da estrutura conceitual utilizada para a elaboração da fundamentação teórica. Esta seção abrange as iniciativas sustentáveis de produção de moluscos bivalves ao redor do mundo, as ações governamentais brasileiras em prol deste desenvolvimento e a consolidação da padronização na produção de moluscos bivalves no Brasil visando alcançar as exigências internacionais de comércio, segurança e qualidade alimentar. Assim, a primeira etapa se ateve à exploração dos temas relativos às normas e legislações pertinentes a estas produções e a gestão e gerenciamento produtivo da atividade no Brasil e na União Europeia.

Dando sequência ao desenvolvimento da pesquisa, tem-se a etapa 2 (figura 2), que pode ser entendida como o processo de organização e análise dos dados, uma vez 


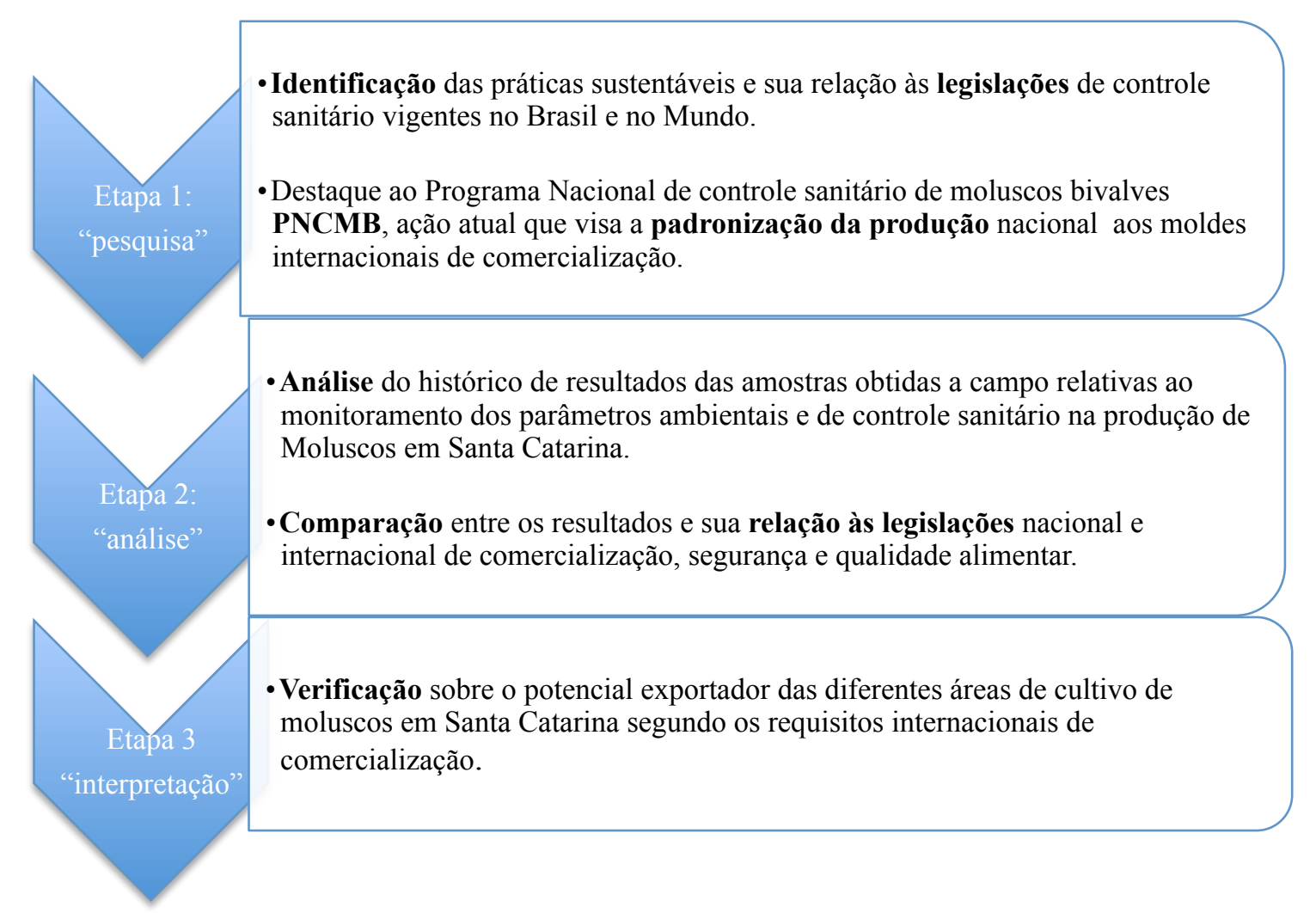

Figura 2 - Etapas para a elaboração da pesquisa.

Figure 2 - Steps for doing research.

que na etapa anterior foram obtidas as informações necessárias para assegurar a confiabilidade das fontes dos dados e entendimento da razão pela qual foram escolhidas. Na primeira fase desta etapa, que constitui a "análise do histórico de resultados das amostras obtidas a campo", foram analisados cerca de 160 relatórios relativos à variável 1 (tabela 4) e 74 relatórios contendo análises conjuntas de ficotoxinas (variável 2) e presença de algas potencialmente nocivas (variável 3 ) ao consumo humano. Cada relatório conjunto das variáveis 2 e 3, exibiu uma média de 6 amostras relativas à variável 2 e 5 amostras relativas à variável 3 , o que gerou um portfólio amostral de 436 e 300 resultados para as variáveis 2 e 3 , respectivamente. Por sua vez, os relatórios da variável 1 são compostos apenas por uma amostra relativa a uma área de extração, razão pela qual a variável 1 apresenta um número maior de relatórios; porém apresentou um número menor de resultados quando comparado às variáveis 2 e 3 .

Tabela 4 - Variáveis analisadas pelo PNCMB em Santa Catarina

Table 4 - Variables analyzed by PNCMB in Santa Catarina

\begin{tabular}{|l|l|}
\hline Variável 1 & $\begin{array}{l}\text { Microrganismos indicadores de poluição } \\
(\text { E. Coli })\end{array}$ \\
\hline Variável 2 & Ficotoxinas \\
\hline Variável 3 & Algas nocivas \\
\hline
\end{tabular}

Tendo estas informações em mãos, passou-se para a segunda fase da etapa 2 , onde foi feita uma comparação entre todos os resultados obtidos nos relatórios das duas variáveis com os padrões exigidos pelas normas internacionais para comercialização de moluscos, tendo-se como foco o mercado unificado da União Européia. Dentro desta perspectiva, a etapa 2 procedeu primeiramente com a separação das variáveis dentro das análises pertinentes à uma mesma área de extração.

Com isso, cada área teve até três análises (variáveis 1, 2 e 3), em um mesmo período, que determinam sua aptidão em termos de parâmetros ambientais para fins de exportação. Em seguida, foram separadas todas as áreas de extração de moluscos existentes nos relatórios emitidos pela CIDASC em Santa Catarina para detalhamento do histórico de resultados obtidos desde o começo da fase de operação do PNCMB, ocorrida em setembro de 2012. A partir daí, foram comparados estes resultados para cada área de extração (por exemplo, nas regiões do Ribeirão da Ilha, Caieira da Barra do Sul, Ponta do Papagaio, etc.) com os limites exigidos por lei (vide tabela 4).

Chegou-se por fim à etapa 3 da pesquisa, que apresenta características empíricas ao se utilizarem dados reais coletados do ambiente para servirem como fonte de dados a análises posteriores. Assim, por meio de uma análise descritiva comparativa, criou-se uma classificação baseada nos parâmetros ambientais registrados 
em campo, contendo todos os resultados amostrais dos pontos de coleta do estado de Santa Catarina para terse, assim, um ranking das áreas mais aptas à comercialização de moluscos bivalves. A partir daí compararamse estes resultados com os regulamentos internacionais de padronização e segurança alimentar requeridos para o processo de exportação de moluscos bivalves, para então ser discutida a viabilidade de inserção dos moluscos de Santa Catarina no mercado global de comercialização do produto.

\section{Resultados e discussão}

Partindo para um contexto mais aplicado, tem-se o PNCMB como a iniciativa que melhor representou o desenvolvimento esperado para a atividade de produção de moluscos bivalves nos últimos anos. Desde seu lançamento em 2012 através da Instrução Normativa Interministerial $\mathrm{n}^{\mathrm{o}} 7$, de 8 de maio de 2012 (tabela 1), são realizados constantes monitoramentos em todas as regiões produtoras de moluscos em Santa Catarina. O objetivo deste controle quanto aos parâmetros ambientais surge pela necessidade de se padronizar tanto os procedimentos utilizados como os cuidados a serem tomados afim de manter a qualidade e segurança alimentar dos produtos gerados desta produção.

Foram monitorados um total de 21 pontos durante o período desta pesquisa, que teve como janela temporal o período entre setembro de 2012 e dezembro de 2013, fechando 15 meses de registros. Destas 21 regiões ou áreas de extração de moluscos em que foi feita a coleta de amostras de seus parâmetros ambientais, somente 15 vêm sendo monitoradas com frequência (pois possuem relatórios e históricos de amostragem) e, segundo a CIDASC, somente 13 são o foco do monitoramento constante pela entidade. São elas: 1 - Freguesia do Ribeirão; 2 - Biguaçu; 3 - Costeira do Ribeirão; 4 Caieira da Barra do Sul; 5 - Ponta do Papagaio; 6 Praia do Cedro; 7 - Ganchos de Fora; 8 - Fazenda Armação; 9 - Zimbros; 10 - Canto Grande; 11 Armação do Itapocorói; 12 - Paulas; 13 - Laranjeiras.

A escolha destas localidades pela CIDASC para servirem como pontos de coleta e amostragem para o PNCMB não foi por acaso, pois fazendo-se uma distribuição destas localidades por regiões litorâneas maiores, tem-se uma cobertura abrangendo quase a totalidade dos pólos produtivos de Santa Catarina. A tabela 5 traz os pontos de coleta selecionados e sua relação às grandes regiões litorâneas produtoras de moluscos bivalves do estado.

Através do histórico destes resultados, torna-se possível detectar características intrínsecas do ambiente de cada região, pois os resultados refletem, na realidade, a movimentação de águas e correntes de uma determinada região, intensidade de dispersão de efluentes, sazonalidade de ocupação destas áreas (válido para regiões como a Ponta do Papagaio, Canto Grande, Zimbros, etc.), entre outras características. Estas características serão melhor detalhadas na análise da tabela 6, que traz o histórico de resultados amostrais para detecção de coliformes em todos os pontos monitorados pela CIDASC em Santa Catarina.

Tabela 5 - Pontos de coleta e amostragem monitorados pela CIDASC em Santa Catarina

Table 5 - Collection and sampling points monitored by CIDASC in Santa Catarina

\begin{tabular}{|c|c|}
\hline Localidade & Região produtora \\
\hline Laranjeiras & \multirow{2}{*}{ São Francisco do Sul } \\
\hline Paulas & \\
\hline Penha & Penha \\
\hline Zimbros & \multirow{3}{*}{ Porto Belo/Bombinhas } \\
\hline Canto Grande & \\
\hline Porto Belo & \\
\hline Fazenda Armação & \multirow{2}{*}{ Governador Celso Ramos } \\
\hline Ganchos de Fora & \\
\hline Praia de São Miguel & Biguaçu \\
\hline Freguesia do Ribeirão da Ilha & \multirow{4}{*}{ Florianópolis } \\
\hline Costeira do Ribeirão da Ilha & \\
\hline Caieira da Barra do Sul & \\
\hline Sambaqui & \\
\hline Praia do Cedro & \multirow{2}{*}{ Palhoça } \\
\hline Ponta do Papagaio & \\
\hline
\end{tabular}

$\mathrm{O}$ registro sobre os micro-organismos indicadores de poluição fecal (neste caso sobre a presença de E. coli) presentes na água, constitui um fator importante, pois pode limitar ou até mesmo suspender o cultivo e/ou utilização da água para diversos fins, inclusive para a atividade de ostreicultura (Miotto, 2009; ACAq, 2013). Este histórico de resultados mostrado na tabela 6, evidencia os registros satisfatórios, aceitáveis e inaceitáveis segundo a normativa Interministerial $\mathrm{n}^{0} 7$ de 2012, que detalha limites e condicionantes (tabela 3) para a comercialização de moluscos bivalves.

Através destes registros, pôde-se analisar a frequência com que as localidades produtoras de moluscos vêm sendo monitoradas e com isto aprimorar a gestão da atividade à medida em que estes registros atingem pontos alarmantes ou que podem pôr em risco a saúde dos consumidores de moluscos bivalves. Ao analisar a tabela 6, torna-se evidente, por exemplo, que localidades como Paulas, Porto Belo e Zimbros carecem de um monitoramento mais acentuado, pois foram as áreas com os maiores registros quanto à presença de $E$. coli nas amostras analisadas (16.000 NMP/100g de amostra). Mesmo apresentando altos índices de microorganismos indicadores de poluição fecal quando 
Tabela 6 - Histórico dos resultados de monitoramento para análise de micro-organismos indicadores de poluição em Santa Catarina. Informações colhidas na CIDASC.

Table 6 - History of the monitoring results for analysis of microorganisms indicators of pollution in Santa Catarina. Information collected at CIDASC.

\begin{tabular}{|c|c|c|c|c|c|c|c|}
\hline \multirow[b]{2}{*}{ Data da Coleta } & \multicolumn{7}{|c|}{$\begin{array}{l}\text { ÁREAS MONITORADAS EM SANTA CATARINA } \\
\text { NMP de } E \text {. coli (NMP/100g de produto) }\end{array}$} \\
\hline & Caieira & Canto Grande & Costeira & Fazenda & Freguesia & Ganchos & Laranjeiras \\
\hline \multicolumn{8}{|l|}{2012} \\
\hline \multicolumn{8}{|l|}{ Set/12 } \\
\hline Out/12 & $<20$ & 9200 & 40 & 20 & 50 & 330 & \\
\hline Nov/12 & 1200 & 3500 & 1300 & 5400 & 5400 & 220 & 330 \\
\hline Dez/12 & $<20$ & & $<20$ & & 140 & 20 & \\
\hline \multicolumn{8}{|l|}{2013} \\
\hline Mar/13 & $<20$ & & $<20$ & & $<20$ & & \\
\hline Abr/13 - 1a Etapa & & 5400 & 40 & & $<20$ & 70 & 20 \\
\hline Abr/13 - 2a Etapa & $<20$ & 20 & 20 & 3500 & 110 & 20 & $<20$ \\
\hline Mai/13 - 1a Etapa & & & & 3500 & & & \\
\hline Mai/13 - 2a Etapa & $<20$ & 270 & $<20$ & & $<20$ & 50 & 50 \\
\hline Jun/13 - 1a Etapa & & 50 & 20 & $<20$ & & & \\
\hline Jun/13 - 2a Etapa & & $<20$ & 50 & 1700 & $<20$ & $<20$ & $<20$ \\
\hline Jul/13 - 1a Etapa & 20 & & 20 & 20 & 20 & & $<20$ \\
\hline Jul/13 - 2a Etapa & $<20$ & & $<20$ & & 330 & & 1800 \\
\hline Jul/13 - 3a Etapa & 50 & 9.200 & 20 & & 170 & & 80 \\
\hline Ago/13 - 1a Etapa & 80 & 790 & $<20$ & & $<20$ & 1.300 & \\
\hline Ago/13 - 2a Etapa & $<20$ & 80 & $<20$ & 330 & 230 & $<20$ & 50 \\
\hline Set/13 - 1a Etapa & 80 & & $<20$ & 130 & $<20$ & 220 & \\
\hline Set/13 - 2a Etapa & 330 & 5.400 & $<20$ & & 20 & 230 & 1.300 \\
\hline Set/13 - 3a Etapa & 1.300 & & $<20$ & 170 & 2.200 & & \\
\hline Out/13 - 1a Etapa & & 490 & & & & & $<20$ \\
\hline Out/13 - 2a Etapa & 40 & 80 & $<20$ & & $<20$ & & \\
\hline Out/13 - 3a Etapa & 50 & 80 & 110 & $<20$ & 110 & 230 & $<20$ \\
\hline Nov/13 - 1a Etapa & & 170 & 20 & & $<20$ & & $<20$ \\
\hline Nov/13 - 2a Etapa & 490 & & 80 & 1300 & 20 & 80 & \\
\hline Nov/13 - 3a Etapa & & 5.400 & & & & & 210 \\
\hline Dez/13 - 1a Etapa & & & & $<20$ & $<20$ & 40 & 50 \\
\hline Dez/13 - 2a Etapa & 20 & & $<20$ & & & & \\
\hline Quantidade de amostras & 18 & 16 & 22 & 13 & 21 & 14 & 15 \\
\hline \% em relação ao total & $69 \%$ & $61 \%$ & $84 \%$ & $50 \%$ & $81 \%$ & $54 \%$ & $57 \%$ \\
\hline Amostras satisfatórias & 9 & 2 & 16 & 5 & 12 & 4 & 7 \\
\hline$\%$ resultados satisfatórios & $50 \%$ & $13 \%$ & $73 \%$ & $38 \%$ & $57 \%$ & $29 \%$ & $47 \%$ \\
\hline
\end{tabular}


Tabela 6 (cont.)- Histórico dos resultados de monitoramento para análise de micro-organismos indicadores de poluição em Santa Catarina. Informações colhidas na CIDASC.

Table 6 (cont.) - History of the monitoring results for analysis of microorganisms indicators of pollution in Santa Catarina. Information collected at CIDASC.

\begin{tabular}{|c|c|c|c|c|c|c|c|}
\hline & \multicolumn{7}{|c|}{$\begin{array}{l}\text { ÁREAS MONITORADAS EM SANTA CATARINA } \\
\text { NMP de } E \text {. coli (NMP } / 100 \mathrm{~g} \text { de produto) }\end{array}$} \\
\hline Data da Coleta & Paulas & Penha & $\begin{array}{c}\text { Pta. do } \\
\text { Papagaio }\end{array}$ & $\begin{array}{c}\text { Porto } \\
\text { Belo }\end{array}$ & $\begin{array}{l}\text { P. do } \\
\text { Cedro }\end{array}$ & $\begin{array}{c}\text { São } \\
\text { Miguel }\end{array}$ & Sambaqui \\
\hline \multicolumn{8}{|l|}{2012} \\
\hline \multicolumn{8}{|l|}{ Set/12 } \\
\hline Out/12 & & 9200 & & & & 330 & \\
\hline Nov/12 & & 9200 & 2800 & & 1300 & 220 & \\
\hline Dez/12 & & & 80 & & 490 & 110 & \\
\hline \multicolumn{8}{|l|}{2013} \\
\hline Mar/13 & & & $<20$ & & & & 1300 \\
\hline Abr/13 - 1a Etapa & 330 & & $<20$ & & 790 & $<20$ & \\
\hline $\mathrm{Abr} / 13$ - 2a Etapa & 70 & & 20 & 130 & 20 & 20 & 940 \\
\hline Mai/13 - 1a Etapa & & & $<20$ & & 50 & $<20$ & \\
\hline Mai/13 - 2a Etapa & 50 & $<20$ & $<20$ & 50 & $<20$ & $<20$ & 70 \\
\hline Jun/13 - 1a Etapa & $<20$ & 110 & 110 & $<20$ & 140 & & 130 \\
\hline Jun/13 - 2a Etapa & 330 & $<20$ & $<20$ & 490 & 50 & $<20$ & 170 \\
\hline Jul/13 - 1a Etapa & 170 & 790 & $<20$ & 20 & & $<20$ & 230 \\
\hline Jul/13 - 2a Etapa & 130 & $<20$ & 20 & 80 & 490 & $<20$ & \\
\hline Jul/13 - 3a Etapa & & 50 & & 16.000 & 20 & & 60 \\
\hline Ago/13 - 1a Etapa & 80 & & $<20$ & 5400 & & 490 & \\
\hline Ago/13 - 2a Etapa & & 230 & 20 & 80 & 270 & $<20$ & \\
\hline Set/13 - 1a Etapa & & & $<20$ & & $<20$ & $<20$ & \\
\hline Set/13 - 2a Etapa & 16.000 & 3.500 & 20 & 330 & 20 & & 330 \\
\hline Set/13 - 3a Etapa & & & 490 & & 220 & 50 & 1.300 \\
\hline Out/13 - 1a Etapa & 790 & 80 & & 110 & & & \\
\hline Out/13 - 2a Etapa & & & $<20$ & 330 & $<20$ & 20 & 270 \\
\hline Out/13 - 3a Etapa & 170 & 80 & 50 & 80 & 50 & 20 & 2.400 \\
\hline Nov/13 - 1a Etapa & 260 & 20 & $<20$ & 120 & 80 & & 50 \\
\hline Nov/13 - 2a Etapa & & & 50 & & 790 & 20 & 170 \\
\hline Nov/13 - 3a Etapa & 700 & 120 & & 330 & & & \\
\hline Dez/13 - 1a Etapa & 20 & & $<20$ & & & & $<20$ \\
\hline Dez/13 - 2a Etapa & & 130 & & 20 & 90 & 330 & \\
\hline Quantidade de amostras & 14 & 15 & 21 & 17 & 19 & 18 & 14 \\
\hline \% em relação ao total & $54 \%$ & $57 \%$ & $81 \%$ & $65 \%$ & $73 \%$ & $69 \%$ & $54 \%$ \\
\hline Amostras satisfatórias & 2 & 4 & 15 & 2 & 6 & 12 & 1 \\
\hline$\%$ resultados satisfatórios & $14 \%$ & $27 \%$ & $71 \%$ & $12 \%$ & $32 \%$ & $67 \%$ & $7 \%$ \\
\hline
\end{tabular}


comparados às outras localidades no mesmo período, deve-se analisar a fundo o porquê destes números, pois em todos os três casos este registro aconteceu de forma pontual e somente em uma das diversas coletas registradas desde a implantação do PNCMB, em 2012.

Contudo, as diretrizes e a Portaria $\mathrm{n}^{\circ} 204$, que regulamentam os procedimentos de controle para a comercialização de moluscos bivalves no Brasil, consideram estes valores razoáveis para se efetivar o comércio de moluscos, sendo necessária somente a inclusão de uma etapa intermediária no processamento do produto, chamada de depuração. Este processo consiste em manter os moluscos em um ambiente com água corrente e livre de contaminantes para, ao longo de algumas horas, desintoxicar a carne dos mesmos através do processo de filtração, natural destas espécies (Leal, 2008; Miotto, 2009; MPA, 2013).

A partir do histórico de participação e frequência de resultados satisfatórios de cada área de extração e/ou cultivo dentro deste processo de monitoramento, foi elaborado um ranking (tabela 7) contendo todas as localidades produtoras de moluscos de Santa Catarina que vêm sendo monitoradas pelo PNCMB. Esta classificação emerge em meio à necessidade de se ampliar o conhecimento sobre tais ações, divulgando o desempenho de cada localidade dentro desse processo de monitoramento e, melhorando desta maneira, os cuidados que devem ser tomados em prol da melhoria na padronização da produção de moluscos no sul do país.

Tabela 7 - Ranking das localidades produtoras de moluscos em Santa Catarina.

Table 7 - Ranking of producing of molluscs in Santa Catarina.

\begin{tabular}{|c|l|}
\hline Classificação & Área de extração e/ou cultivo \\
\hline 1 & Costeira do Ribeirão da ilha \\
\hline 2 & Ponta do Papagaio \\
\hline 3 & Praia de São Miguel \\
\hline 4 & Freguesia do Ribeirão da ilha \\
\hline 5 & Caieira da Barra do Sul \\
\hline 6 & Laranjeiras \\
\hline 7 & Fazenda Armação \\
\hline 8 & Praia do Cedro \\
\hline 9 & Ganchos de Fora \\
\hline 10 & Zimbros \\
\hline 11 & Penha \\
\hline 12 & Canto Grande \\
\hline 13 & Paulas \\
\hline
\end{tabular}

As análises sobre as outras variáveis, também alvos de monitoramento pelo PNCMB em Santa Catarina, que são as ficotoxinas e análise sobre o potencial de presença de algas nocivas, não registraram, ao longo deste trabalho, a ocorrência de manifestações que pudesse por em risco a saúde dos consumidores de moluscos bivalves. Todavia, no mês de abril de 2013, foi constatada a presença de uma ficotoxina da espécie DSP (Diarrheic Shellfish Poisoning), quando, então, foram solicitadas mais algumas coletas da mesma localidade para se avaliar o potencial de dispersão desta microalga pelo ambiente. Em algumas horas o evento se dissipou, não apresentando grandes transtornos aos produtores (ACAq, 2013).

Na biota marinha nativa de Santa Catarina, existem alguns tipos de microalgas, como é o caso do gênero Pseudo-nitzschia, que às vezes aparece em pequenas concentrações nos relatórios expedidos pela CIDASC. Segundo Barbieri (2009), estas diatomáceas são responsáveis pela concentração do ácido domoico (DA - Domoic Acid), que pode levar à doença característica da ASP (Amnesic Shellfish Poisoning), mas não nestas concentrações, não apresentando, portanto, na atualidade, perigo para a saúde e o consumo de moluscos bivalves (MPA, 2013). Outra alga encontrada nos relatórios expedidos pela CIDASC foi do gênero Dinophysis, promotora das DSP (Diarrheic Shellfish Poisoning). As algas pertencentes a esse gênero são responsáveis pela maioria das causas envolvendo o consumo de moluscos e problemas de ordem gastrointestinal (Svensson, 2003; Barbieri, 2009). Todavia, não foram encontradas nas análises.

\section{Conclusões}

O objetivo principal deste artigo foi realizar uma análise comparativa entre os resultados do Programa Nacional de Controle Higiênico-Sanitário de Moluscos Bivalves em Santa Catarina e os padrões internacionais de comercialização de moluscos bivalves, mais precisamente na atividade da ostreicultura.

Ao longo deste ano e três meses de coletas e registros dos parâmetros ambientais necessários para tal, já se pôde constatar a dinâmica da qualidade ambiental destas localidades produtivas. Tomando-se em consideração que as áreas de cultivo responsáveis por mais de $80 \%$ da produção de moluscos em Santa Catarina estão entre os oito primeiros da classificação gerada a partir destes resultados, tem-se a garantia de um produto naturalmente saudável. Soma-se a isso o fato de que, segundo a legislação nacional e internacional de comércio para os moluscos bivalves, todas as localidades de Santa Catarina monitoradas pelo PNCMB, apresentaram condições boas e/ou aceitáveis em seu histórico de resultados.

Como registrado nos próprios resultados amostrais ao longo desta pesquisa, a dinâmica das águas é, muitas vezes, imprevisível. Deste modo, não se pode garantir a inocuidade de um produto somente com análises de 
coliformes totais, mas opera-se junto a isso o desenvolvimento de novos indicadores e diretrizes que, formulados localmente, irão prevenir com eficácia a contaminação dos produtos daquela região. Neste sentido é que o Regulamento CE $\mathrm{n}^{0} 854 / 2004$ classifica as zonas de produção de moluscos ao redor do mundo, fortalecendo assim a necessidade de monitoramento e padronização dos vieses produtivos e exigências de cada região em relação aos requisitos necessários para uma comercialização segura.

Pela legislação em vigor atualmente no Brasil, todos os limites amostrais, conforme a Portaria $\mathrm{n}^{\circ} 204$ de 28 junho de 2012 e sua correspondente internacional (Regulamento $\mathrm{n}^{0} \quad 853 / 2004$ e Regulamento $\mathrm{n}^{0}$ 2074/2005) apresentaram resultados em conformidade para comércio de produtos derivados de moluscos bivalves. Sendo assim, uma vez enquadrados dentro dos limites da legislação nacional, os mesmos produtos estão aptos à sua inserção no mercado europeu de moluscos. Assim, na análise destes parâmetros e através das 868 coletas realizadas pela CIDASC sobre estas variáveis, pôde-se constatar uma boa qualidade da água das áreas de extração e/ou cultivo de moluscos bivalves no que tange à presença de ficotoxinas e algas nocivas ao consumo humano.

\section{Referências bibliográficas}

ACAq (2013) - Relatório da Reunião da ACAq realizada no dia 14/03/2013. [Relatório disponível na web page]. Associação Catarinense de Aqüicultura (ACAq), Florianópolis, SC, Brasil. Disponível on-line em http://acaqsc.blogspot.com.br/

Barbieri, E. (2009) - O Perigo das Biotoxinas Marinhas. São Paulo: 31p., Texto Técnico, Instituto de Pesca, São Paulo, SP, Brasil. Disponível on-line em ftp://ftp.sp.gov.br/ftppesca/ texto_tecnico barbieri.pdf.

Buanes, A.; Jentoft, S.; Maurstad, A.; Søreng, S.U.; Runar Karlsen, G. (2005) - Stakeholder participation in Norwegian coastal zone planning. Ocean \& Coastal Management, 48(9-10):658-669. DOI: 10.1016/j.ocecoaman.2005.05.005.

Cicin-Sain, B; Belfiore, S. (2005) - Linking marine protected areas to integrated coastal and ocean management: a review of theory and practice. Ocean \& Coastal Management, 48(11-12):847868. DOI: 10.1016/j.ocecoaman.2006.01.001

FAO (2012) - The State of World Fisheries and Aquaculture. Opportunities and challenges. Food and Agriculture Organization of the United Nations. 223p., Food and Agriculture Organization of the United Nations (FAO), Roma, Itália. ISBN 978-9251082751. Disponível on-line em http://www.fao.org/3/a-i3720e.pdf

Goṇi, R. (1998) - Ecosystem effects of marine fisheries: an overview. Ocean \& Coastal Management, 40(1):(37-64). DOI: 10.1016/S0964-5691(98)00037-4

Humphrey, S.; Burbridge, P.; Blatch, C. (2000) - US lessons for coastal management in the European Union. Marine Policy, 24(4):275-286. DOI: $10.1016 / \mathrm{S} 0308-597 \mathrm{X}(00) 00003-8$

ICES (2009) - Report of the Working Group on Marine Shellfish Culture (WGMASC). 91p., International Council for the Exploration of the Sea, Copenhagen, Denmark. Disponível online em http://archimer.ifremer.fr/doc/00041/15202/12529.pdf
Todavia, não basta somente o desempenho ótimo dos parâmetros naturais se a sequência da cadeia produtiva não estiver adaptada aos requisitos. Este foi um ponto ressaltado pelo "pacote de higiene" constituído pelos Reg. $n^{\circ} 852 / 2004$ Reg. $n^{\circ} 853 / 2004$ e Reg. $n^{0} 854 / 2004$. Nele impõe-se a obrigatoriedade de implementação dos procedimentos baseados nos princípios do HACCP para todos os estabelecimentos que pretendem comercializar seus produtos alimentícios, incluído os moluscos bivalves, no mercado comunitário da Europa. Somente após a devida adaptação do setor de processamento de moluscos é que obteremos, gradativamente, a padronização da produção de moluscos bivalves e a consolidação da atividade de cultivo de ostras como uma forma segura de produção no que tange à saúde de seus produtos, comércio e consumo dos mesmos.

Como recomendações para trabalhos futuros, sugere-se que sejam realizadas novas pesquisas que visem o aprofundamento na utilização de softwares simuladores de cenários como ferramenta auxiliadora na manutenção do nível sustentável de cultivos e a realização de pesquisas nas áreas complementares à produção, como o desenvolvimento de maquinários para a otimização dos processos produtivos da cadeia produtiva de moluscos bivalves.

Inácio, P. (2008) - Implicações do Pacote de Higiene no setor da Pesca - Comparação entre as regras anteriores e o novo enquadramento legal. Segurança e Qualidade Alimentar (ISSN: 1646-6349), 4:6-8, Editideias, Lisboa, Portugal. Disponível online em http://www.infoqualidade.net/SEQUALI/PDFSEQUALI-04/n4-sequali-06.pdf

Leal, D.A.G. (2008) - Moluscos bivalves destinados ao consumo humano como vetores de protozoários patogênicos: métodologias de detecção e normas de controle. Revista Panamericana de Infectologia (ISSN: 1679-7140), 4:48-57, Bevilacqua Editora, São Paulo, SP, Brasil. Disponível on-line em $\mathrm{http} / / / \mathrm{www}$.revistaapi.com/wp-content/uploads/2014/03/mat-081.pdf

Mccausland, W.D.; Mente, E.; Pierce, G.J.; Theodossiou, I. (2006) A simulation model of sustainability of coastal communities: aquaculture, fishing, environment and labour markets. Ecological Modelling, 193(3-4):271-294. DOI: 10.1016/ j.ecolmodel.2005.08.028

Miotto, L.A. (2009) - Coliformes termotolerantes e enterococcus SP em ostras e águas salinas utilizadas para cultivo de moluscos bivalves da Baia Sul da Ilha de Santa Catarina-Brasil. 104p., Dissertação de Mestrado em Ciências do Alimento, Universidade Federal de Santa Catarina, Florianópolis, SC, Brasil. Não publicado.

MPA (s/d) - Aquicultura. [web page]. Ministério da Pesca e Aquicultura, Brasília, Brasil. Disponível on-line em http://mpa.gov.br/index.php/aquicultura

Rangeley, R.W.; Davies, R.W.D. (2012) Raising the "Sunken Billions": Financing the transition to sustainable fisheries. Marine Policy, 36(5):1044-1046. DOI: 10.1016/j.marpol. 2012.02.020

Santos, A.A. dos; Novaes, A.L.T.; Silva, F.M.; Souza, R.V; Sérgio Winckler da Costa, S.W.; Guzenski, J. (2013) - Sintese 
Informativa da Maricultura 2012. 7p., Empresa de Pesquisa Agropecuária e Extensão Rural de Santa Catarina (Epagri), Florianópolis, SC, Brasil. Disponível on-line em http://www. epagri.sc.gov.br/wp-content/uploads/2013/08/Síntese-informati va-da-maricultura-2012-4.pdf

Soniat, T. M.; Klinck, J.M.; Powell, E.N.; Cooper, N.; Abdelguerfi, M.; Hofmann, E.E.; Dahal, J.; Tu, S.; Finigan, J.; Eberline, B.S.; La Peyre, J.F.; La Peyre, M.K.; Qaddoura, F. (2012) - A ShellNeutral Modeling Approach Yields Sustainable Oyster Harvest Estimates: A Retrospective Analysis of the Louisiana State Primary Seed Grounds. Journal of Shellfish Research, 31(4):1103-1112. DOI: 10.2983/035.031.0421

Svensson, S. (2003) Depuration of Okadaic acid (Diarrhetic Shellfish Toxin) in mussels, Mytilus edulis (Linnaeus), feeding on different quantities of nontoxic algae. Aquaculture, 218(14):277-291. DOI: 10.1016/S0044-8486(02)00504-5

Tacon, A.G.J.; Forster, I.P. (2003) - Aquafeeds and the environment: policy implications. Aquaculture, 226(1-4):181189. DOI: $10.1016 / \mathrm{S} 0044-8486(03) 00476-9$
Thorpe, A.; Reid, C.; van Anrooy, R.; Brugere, C. (2005) - When fisheries influence national policy-making: an analysis of the national development strategies of major fish-producing nations in the developing world. Marine Policy, 29(3):211-222. DOI: 10.1016/j.marpol.2004.05.004

Tiller, R.; Gentry, R.; Richards, R. (2013) - Stakeholder driven future scenarios as an element of interdisciplinary management tools; the case of future offshore aquaculture development and the potential effects on fishermen in Santa Barbara, California. Ocean \& Coastal Management, 73:127-135. DOI: 10.1016/j.ocecoaman.2012.12.011

Troell, M.; Halling, C.; Neori, A.; Chopin, T.; Buschmann, A.H.; Kautsky, N.; Yarish, C. (2003) - Integrated mariculture: asking the right questions. Aquaculture, 226(1):69-90. DOI: 10.1016/S0044-8486(03)00469-1

Vianna, L.F.N.; Bonetti, J.; Polette, M. (2012) - Gestão costeira integrada: análise da compatibilidade entre os instrumentos de uma política pública para o desenvolvimento da maricultura e um plano de gerenciamento costeiro no Brasil. Revista Gestão Costeira Integrada, 12(3):357-372. DOI: 10.5894/rgci335 